\title{
El reconocimiento y la anulación de laudos arbitrales extranjeros en Colombia: un análisis de la jurisprudencia de la Corte Suprema de Justicia**
}

DOI: dx.doi.org/10.15425/2017.353

\section{Resumen}

La Corte Suprema de Justicia ha establecido a través de su jurisprudencia que su competencia en los procedimientos de reconocimiento y anulación de laudos arbitrales extranjeros debe guiarse y limitarse por el principio de mínima intervención judicial y sus reglas derivadas: (1) la ausencia de un análisis sustancial, (2) la taxatividad e interpretación restrictiva de las causales y (3) la armonización internacional, consecuente con una visión proarbitraje. De esta forma, al interpretar las causales de denegación de reconocimiento y de anulación, ha dado aplicación al principio y sus reglas, y se ha basado y coincidido con los criterios de interpretación existentes en los instrumentos internacionales de soft law y hard law, así como en la doctrina y la jurisprudencia internacionales, adoptando una perspectiva internacional y deslocalizada del arbitraje en estos procedimientos.

\section{Palabras clave}

Arbitraje comercial internacional, reconocimiento y anulación de laudos arbitrales extranjeros, Corte Suprema de Justicia, análisis jurisprudencial, principio de mínima intervención judicial.

* Abogado de la Universidad Nacional de Colombia. Asociado del Equipo de Litigios, Arbitraje e Insolvencia de Brigard Urrutia. Miembro del Comité Colombiano de Arbitraje y del Consejo Directivo de la Red Juvenil de Arbitraje del Centro de Arbitraje y Conciliación de la Cámara de Comercio de Bogotá. Correo electrónico: josecano2506@gmail.com.

** Este artículo constituye una opinión de carácter personal y con fines eminentemente académicos. 


\title{
Recognition, enforcement and annulment of foreign arbitral awards in Colombia: An analysis of the case law of the Supreme Court of Justice
}

\begin{abstract}
The Colombian Supreme Court of Justice has established through its case law that its competence in the procedures for recognition, enforcement and annulment of foreign arbitral awards must be guided and limited by the principle of minimum judicial intervention and its derived rules: (1) the absence of an analysis on the merits of the award, (2) the narrow interpretation of the grounds and (3) the international harmonization, consistent with a pro-arbitration bias. Thus, it has interpreted the grounds for refusing recognition and enforcement and for annulment by applying the principle and its rules, and by relying on the interpretation criteria that exist in soft law and hard law international instruments, and in the international doctrine and case law. Therefore, the Court has adopted an international and delocalized perspective within these proceedings.
\end{abstract}

\section{Keywords}

International commercial arbitration, recognition and enforcement of foreign arbitral awards, annulment of foreign arbitral awards, Colombian Supreme Court of Justice, case law analysis, principle of minimum judicial intervention. 


\section{Introducción}

El arbitraje comercial internacional ha adquirido gran importancia en el contexto económico y jurídico actual por ser uno de los métodos de solución de controversias por excelencia en las relaciones comerciales internacionales ${ }^{1-2}$. Ahora bien: la materialización de la solución que brinda el arbitraje requiere que la decisión de los árbitros sea reconocida y surta plenos efectos en la jurisdicción donde se pretende ejecutar. En este punto cobran relevancia el reconocimiento y la anulación de laudos arbitrales extranjeros, pues a través de estos procedimientos el órgano judicial competente del país donde se pretende ejecutar el laudo arbitral resuelve sobre la fuerza vinculante de este y los cuestionamientos a su validez $z^{3}$.

Teniendo en cuenta la relevancia de estos procedimientos, en todo el mundo se ha buscado garantizar su carácter internacional y su uniformidad. Para tal fin se creó la Convención de Nueva York de $1958^{[4]}$ (en adelante, la CNY) ${ }^{5}$, la cual, a medida que ha sido ratificada, ha permitido la unificación de las causales de denegación de reconocimiento de laudos extranjeros y la eliminación de requisitos particulares de cada país ${ }^{6-7}$. Igualmente, la Comisión de las Naciones Unidas para el Derecho Mercantil Internacional diseñó una ley modelo sobre arbitraje comercial internacional que acogió las mismas causales para denegar el reconocimiento ${ }^{8} \mathrm{y}$

1 Según las estadísticas de la Cámara de Comercio Internacional, desde su creación la Corte de Arbitraje ha administrado 25.000 casos. Tan solo en 2019 se recibieron 869 nuevos casos, lo cual significa que un gran número de disputas son resueltas mediante arbitraje internacional comercial, sin contar otras instituciones o arbitrajes de otra naturaleza. Al respecto, véase "ICC celebrates case milestone, announces record figures for 2019", International Chamber of Commerce, acceso el 25 de abril de 2020, https://iccwbo.org/media-wall/news-speeches/icc-c elebrates-25000th-case-milestone-and-announces-record-figures-for-2019/.

2 Marco Monroy, Arbitraje Comercial Nacional e Internacional (Bogotá: Librería Ediciones El Profesional, 2017), 134.

3 Nigel Blackaby, Constantine Partasides, Alan Redfern y Martin Hunter, Redfern and Hunter on International Arbitration (Oxford: Oxford, 2009), 625.

4 Convención sobre el Reconocimiento y Ejecución de las Sentencias Arbitrales Extranjeras, 10 de junio de 1958.

$5 \quad$ La CNY fue ratificada por Colombia mediante la Ley 39 de 1990. Al respecto, véase la Ley 39 de 1990, 20 de noviembre. Diario Oficial 39.587.

$6 \quad$ El artículo $5 .^{\circ}$ de la CNY contiene estas causales.

7 Según la CNUDMI, la CNY cuenta con 163 estados parte, lo cual facilita en gran medida el reconocimiento de laudos extranjeros. Al respecto, véase "Status Convention on the Recognition and Enforcement of Foreign Arbitral Awards", United Nations Comission on International Trade Law, acceso el 21 de abril de 2020, https://uncitral.un.org/en/texts/arbitration/conventions/ foreign_arbitral_awards/status2. 
recogió y unificó las causales para la anulación (en adelante, la "Ley Modelo") 9-10-11. Siguiendo este marco jurídico, Colombia adoptó legalmente estas causales para la denegación del reconocimiento y la anulación ${ }^{12}$, y otorgó legalmente competencia a la Corte Suprema de Justicia (en adelante, la CSJ) para conocer de ambos procedimientos ${ }^{13}$.

En ejercicio de su atribución legal, la CSJ ha establecido a través de su jurisprudencia, desde una perspectiva internacional del arbitraje comercial internacional, que su competencia en los procedimientos de reconocimiento y anulación de laudos extranjeros debe guiarse y limitarse por el principio de mínima intervención judicial y sus reglas derivadas, a saber: (1) la ausencia de un análisis sustancial, (2) la taxatividad e interpretación restrictiva de las causales y (3) la armonización internacional. Con fundamento en lo anterior, la CSJ ha otorgado una interpretación a las causales de denegación de reconocimiento y anulación de laudos arbitrales que recurre a las fuentes internacionales y coincide con sus criterios de interpretación.

En este contexto, el objeto del presente artículo es realizar una exposición del análisis jurisprudencial que en sede de reconocimiento y anulación ha venido realizando la CSJ, con el fin de identificar el alcance que les ha dado al principio de mínima intervención judicial y a sus reglas, así como estudiar la interpretación que, con base en este principio, les ha atribuido a las causales de reconocimiento y anulación de laudos extranjeros. En todo caso, se aclara que el presente artículo se refiere únicamente al arbitraje internacional, mas no al arbitraje doméstico colombiano y, por ende, excluye el análisis de la anulación de laudos nacionales.

De esta manera, en un primer momento se expondrá el entendimiento jurisprudencial de la CSJ sobre el principio de mínima intervención judicial y cada una de sus reglas, para comprender cómo determinan su competencia en estos procedimientos. En segundo lugar, se revisará la interpretación que, con base en el principio, la CSJ ha realizado sobre las causales específicas de denegación de reconocimiento y anulación. Para el efecto se expondrán algunas sentencias donde

9

CNUDMI, Ley Modelo, art. 36.

Blackaby et al., Redfern and Hunter, 697.

Según la CNUDMI, 83 estados y 116 jurisdicciones han adoptado la Ley Modelo. Al respecto, véase "Status: UNCITRAL Model Law on International Commercial Arbitration (1985), with amendments as adopted in 2006", United Nations Commission on International Trade Law, acceso el 21 de abril de 2020, https://uncitral.un.org/en/texts/arbitration/modellaw/commercial_arbitration/status.

2 Ley 1563 de 2012, 12 de julio. Diario Oficial 48.489. Los artículos 108 y 112 de la Ley 1563 de 2012 listan respectivamente las causales de anulación y de denegación del reconocimiento.

Así lo establece el artículo 68 de la Ley 1563 de 2012 cuando las partes del arbitraje son particulares. Sin embargo, cuando una parte sea entidad pública conocerá la Sección Tercera del Consejo de Estado. 
la CSJ abordó las causales de (1) invalidez del pacto arbitral, (2) incongruencia, (3) el procedimiento arbitral no se ajusta al acordado entre las partes y (4) orden público internacional. En un último momento se expondrán algunas conclusiones relevantes derivadas de la revisión de la jurisprudencia de la CSJ.

\section{El principio de mínima intervención judicial: guía y límite de la competencia de la CSJ}

La CSJ ha establecido que su competencia en el análisis de reconocimiento y anulación debe guiarse y está limitada por el principio de mínima intervención judicial. A continuación se realizará una revisión del entendimiento que la CSJ ha dado al principio y a cada una de sus reglas. Igualmente, se expondrá cómo con esta perspectiva la CSJ ha adoptado una visión deslocalizada del arbitraje internacional que se basa en la doctrina y la jurisprudencia internacionales ${ }^{14-15}$, así como en instrumentos internacionales de soft law y hard law ${ }^{16-17}$, y que corresponde con las reglas de interpretación que, de acuerdo con la doctrina, imperan en el campo internacional.

\section{A) El principio de mínima intervención judicial}

Para la CSJ, este principio impone un análisis judicial limitado a "aspectos extrínsecos de la decisión sustancial adoptada por los árbitros"18 y obedece a la naturaleza

14 La CSJ ha citado al doctrinante Gary Born. Al respecto, véase CSJ, Cas. Civil. Sent. ene. 15/2019, SC 001-2019, rad. 11001-02-03-000-2016-03020-00. MP: Aroldo Wilson Quiroz. Asunto: Recurso extraordinario de anulación de laudo arbitral, 2.

15 La CSJ ha citado a la Corte Suprema de Hong Kong, el Tribunal de Apelaciones del Segundo Distrito de los Estados Unidos, el Tribunal Federal de Australia, los tribunales alemanes, el Tribunal de Apelación de Inglaterra y Gales, los tribunales italianos y el Tribunal Comercial Superior de la Federación de Rusia. Al respecto, véase CSJ, Cas. Civil. Sent. jul. 12/2017, SC 9909-2017, rad. 11001-02-03-0002014-01927-00. MP: Aroldo Wilson Quiroz. Asunto: Reconocimiento de laudo arbitral, 31; y CSJ, Cas. Civil. Sent. oct. 30/2017, SC 17655-2017, rad. 11001-02-03-000-2016-00479-00. MP: Ariel Salazar Ramírez. Asunto: Reconocimiento de laudo arbitral, 21-22.

16 La CSJ ha hecho referencia a los documentos de la International Bar Association para analizar el valor probatorio de los documentos. Al respecto, véase CSJ, Cas. Civil. Sent. dic. 19/2018, SC 5677-2018, rad. 11001-02-03-000-2017-03480-00. MP: Margarita Cabello Blanco. Asunto: Recurso extraordinario de anulación de laudo arbitral, 55.

17 La CSJ ha citado la recomendación relativa a la interpretación del párrafo 2 de la CNY proferida por la CNUDMI en 2006, para señalar que es deseable "la interpretación y aplicación uniformes de las convenciones internacionales y de las leyes uniformes en el campo del derecho mercantil internacional”. Al respecto, véase CSJ, Cas. Civil. Sent. SC 9909-2017, jul. 12/2017, 22. 
y el fin del arbitraje internacional. De esta manera, la decisión de acudir a arbitraje implica declinar la jurisdicción estatal, es decir, una vez pactado, no es posible volver a ella ${ }^{19}$; así, la intervención judicial en el arbitraje internacional se limita a precisas materias establecidas por la ley que buscan remediar defectos significativos en el proceso arbitral ${ }^{20-21}$.

A su vez, el principio está integrado por un conjunto de reglas que limitan la competencia del juez que conoce del reconocimiento y la anulación: (1) la ausencia de análisis sustancial, (2) la taxatividad de las causales - de la cual se deriva la interpretación restrictiva- y (3) la armonización internacional y una visión proarbitraje $22-23-24-25$.

\section{Ausencia de análisis sustancial}

La CSJ ha sostenido que esta regla se extrae del artículo 107 de la Ley 1563 de 2012 (en adelante, la Ley 1563$)^{26}$, y prohíbe al juzgador pronunciarse sobre el fondo de la controversia, así como calificar los criterios, la motivación y la interpretación del tribunal. De esta forma, la Ley 1563 excluyó cualquier posibilidad de que la anulación se utilizara como una segunda instancia, pues los razonamientos de fondo de los árbitros se vuelven intangibles una vez proferida la decisión; en este sentido, la anulación se limita a asuntos meramente procesales ${ }^{27}$.

Ibíd., 19.

Ídem.

El artículo 67 de la Ley 1563 establece: "Alcance de la intervención de la autoridad judicial. En los asuntos que se rijan por la presente sección, no podrá intervenir ninguna autoridad judicial, salvo en los casos y para los propósitos en que esta sección expresamente así lo disponga".

CSJ, Cas. Civil. Sent. SC 001-2019, ene. 15/2019, 20.

CSJ, Cas. Civil. Sent. SC 9909-2017, jul. 12/2017, 21: “(1) interpretación pro-internacional; (2) principio pro-ejecución o pro-reconocimiento; (3) taxatividad de las causales de denegación; (4) ausencia de revisión sustancial; y (5) doble control".

CSJ, Cas. Civil. Sent. SC 17655-2017, oct. 30/2017, 12: "la no revisión del fondo de la decisión arbitral; [...] la especificidad de las causales de denegación; [...] la carga de la prueba del convocado en cuanto a los motivos invocados para solicitar la desestimación de la citada petición; [...] la existencia de causales que permiten de oficio declarar la improcedencia del reconocimiento".

CSJ, Cas. Civil. Sent. SC 5677-2018, dic. 19/2018, 15-16: La anulación solo puede darse "con soporte en causales taxativas, sin trasladar al juez de la anulación la potestad de examinar el fondo del litigio".

El artículo 107 establece: "Contra el laudo arbitral solamente procederá el recurso de anulación por las causales taxativamente establecidas en esta sección. En consecuencia, la autoridad judicial no se pronunciará sobre el fondo de la controversia ni calificará los criterios, valoraciones probatorias, motivaciones o interpretaciones expuestas por el tribunal arbitral". 
En la sentencia de fecha 21 de julio de $2005^{[28]}$, la CSJ indicó que el recurso de anulación "[n]o se trata [...] de un recurso para revisar o replantear lo que ya fue objeto de decisión mediante arbitramento [...]. Por el contrario, las causales de anulación del laudo miran es el aspecto procedimental del arbitraje"29.

Posteriormente, en la sentencia SC 4766-2014, la CSJ se basó en su anterior decisión con el fin de abordar la naturaleza del recurso de anulación, sosteniendo que las causales de anulación no permiten que sea reexaminada la cuestión material decidida por los árbitros ${ }^{30}$.

De forma más reciente, en las sentencias SC 5207-2017 [31] y SC 5677$2018^{[32]}$, la CSJ desarrolló esta regla, pues señaló que la finalidad del recurso es proteger el derecho al debido proceso, para lo cual puede estudiar errores graves, pero no sustantivos ${ }^{33}$. Así, para la CSJ, las causales están asociadas a vicios procedimentales señalados por el legislador, lo cual impide la valoración probatoria y cuestionar los razonamientos jurídicos del tribunal arbitral ${ }^{34}$.

En específico, en la sentencia SC 5677-2018 la CSJ determinó que el recurso de anulación bajo estudio cuestionaba el fondo de la controversia pues invocaba errores en la valoración probatoria del tribunal, lo cual resultaba suficiente para desestimarlo ${ }^{35}$.

Para resolver el caso, la CSJ se refirió al énfasis que el tribunal arbitral hizo de los dictámenes periciales aportados por las partes y cómo los árbitros confrontaron estas experticias con otras pruebas "con el propósito de establecer la finalización o no del acuerdo negocial que ligaba a las partes, su incumplimiento y los perjuicios que pudieron generarse con ocasión de este" ${ }^{\prime 36}$. También señaló que el laudo dio importancia a las pruebas documentales contenidas en correos electrónicos, comunicaciones entre las partes, y al contrato en cuestión, "del cual realiza

CSJ, Cas. Civil. Sent. jul. 21/2005, rad. 1101-02-03-000-2004-00034-01. MP: Edgardo Villamil Portilla. Asunto: Recurso extraordinario de revisión. Ibíd., 8.

CSJ, Cas. Civil. Sent. abr. 21/2014, SC 4766-2014, rad. 11001-0203-000-2012-01428-00. MP: Ruth Marina Díaz Rueda. Asunto: Recuso extraordinario de revisión.

CSJ, Cas. Civil. Sent. abr. 18/2017, SC 5207-2017, rad. 11001-0203-000-2016-01312-00. MP: Luis Alonso Rico Puerta. Asunto: Recurso extraordinario de anulación de laudo arbitral, 36. CSJ, Cas. Civil. Sent. SC 5677-2018, dic. 19/2018, 17.

Fredy Herrera y Felipe González, "Evolución de la jurisprudencia de la Corte Suprema de Justicia en materia arbitral". YouTube. 13 de febrero de 2019. https://www.youtube.com/watch?v=9 rn9ArsRCmA\&t=1263s. 
interpretación de sus distintas estipulaciones para determinar la viabilidad o no de los reparos y reclamaciones que formularon los extremos procesales" ${ }^{37}$. Con base en lo anterior, la CSJ determinó que el tribunal había realizado un análisis "a partir de una valoración del material arrimado al pleito y amparado en la ley sustancial y jurisprudencias colombianas"38.

Esta postura sostenida por la CSJ en las anteriores sentencias contiene elementos de análisis que se han adoptado por la doctrina en el ámbito internacional. En efecto, los profesores Gary Born ${ }^{39}$ y Nigel Blackaby ${ }^{40}$ han resaltado que es un principio esencial del arbitraje internacional que las cortes nacionales no revisen los elementos sustanciales de las decisiones en sede de reconocimiento, pues su propósito no es decidir si el laudo es correcto jurídica o fácticamente.

Igualmente, el profesor Vladimir Pavic ha señalado que esta regla es un principio que se basa en una perspectiva de laissez-faire del arbitraje, respecto del cual hay unas cuantas excepciones menores en la Ley Modelo y en la CNY, pero que es la norma general| ${ }^{41}$. Igualmente, los profesores Emmanuel Gaillard y Benjamin Siino han señalado que las causales de la CNY no contemplan decisiones erróneas de hecho o derecho por parte de un tribunal arbitral, $y$, en consecuencia, las cortes no pueden revisar los méritos de la decisión del tribunal ${ }^{42}$.

\section{Taxatividad e interpretación restrictiva de las causales}

Para la CSJ esta regla exige que la denegación de reconocimiento y la anulación encajen de forma precisa en una de las causales previstas en los artículos $108^{[43]} \mathrm{y}$ 112 y, como consecuencia, la regla impone que su interpretación sea restrictiva ${ }^{44}$.

lbíd., 39.

Ibíd., 44.

Gary Born, International Arbitration: Law and practice (Alphen aan den Rijn: Kluwer Law International, 2012), 461-462.

Blackaby et al., Redfern and Hunter, 699.

Vladimir Pavic, "Annulment of arbitral awards in international commercial arbitration", en Investment and Commercial Arbitration - Similarities and Divergences, editado por Christina Knahr, Christian Koller, Walter Rechberger y August Reinisch (The Netherlands, Eleven International Publishing, 2010), 136. to Challenging and Enforcing Arbitration Awards, editado por William Rowley (London: Law Business Research, 2019), 94. 
Esta regla fue desarrollada en la sentencia SC 17655-2017 ${ }^{[45]}$, donde se sostuvo que la CNY contiene una lista taxativa de los motivos de denegación de reconocimiento y que, por ende, tal denegación solo será procedente cuando se encuentre probado plenamente uno de dichos motivos. Igualmente, de acuerdo con la CSJ, en virtud de la taxatividad se exige una interpretación restrictiva de las causales. Al respecto, la CSJ citó en esta sentencia la guía del Consejo Internacional para el Arbitraje Comercial para la interpretación de la CNY, según la cual las cortes nacionales deben interpretar de forma restringida las causales para la denegación en aras de favorecer el arbitraje ${ }^{46}$.

Además, y de forma más reciente, en el auto AC 3076-2019 ${ }^{[47]}$, la CSJ determinó que "[e]n materia de arbitraje internacional, el estatuto que lo gobierna previó la posibilidad de acudir al recurso de anulación 'por las causales taxativamente establecidas'" 48 .

La doctrina internacional y nacional sobre arbitraje comercial internacional se ha pronunciado en un mismo sentido sobre la taxatividad al señalar que la CNY señala las únicas causales para negar reconocimiento y que deben ser interpretadas de forma estrecha ${ }^{49-50}$.

Al respecto, es de resaltar que la profesora Margaret Moses ha señalado que la CNY contempla un limitado número de causales para negar el reconocimiento de un laudo extranjero, las cuales deben ser interpretadas restrictivamente y son exhaustivas, es decir, son las únicas causales en las cuales la denegación de reconocimiento puede estar fundada ${ }^{51}$.

Igualmente, los profesores Emmanuel Gaillard y Bejamin Siino han sostenido que, por regla general, las autoridades judiciales de los países han "interpretado las causales para denegación bajo el artículo $\vee$ de forma restrictiva" ${ }^{2}$, e incluso las

CSJ, Cas. Civil. Sent. SC 17655-2017, oct. 30/2017, 28-29. Ibíd., 29.

CSJ, Cas., Civil, Auto ago. 1/2019, AC 3076-2019, rad. 11001-02-03-000-2019-02452-00. MP: Aroldo Wilson Quiroz. Asunto: Recurso extraordinario de anulación de laudo arbitral.

Ibíd., 2.

Nicolás Lozada y Hernando Otero, "Reconocimiento y ejecución de laudos arbitrales internacionales en Colombia ¡Adiós exequátur!", en Arbitraje $360^{\circ}$ La práctica del litigio arbitral. Aspectos contractuales y procesales, editado por Hernando Herrera y Fabricio Mantilla (Bogotá: Editorial Ibáñez, 2017), 389-390.

Born, International Arbitration, 460-461

Margaret Moses, The principles and practices of international commercial arbitration (New York: Cambridge University Press, 2008), 208.

Gaillard y Siino, "Enforcement under the New York Convention”, 94. 
partes que se oponen al reconocimiento han fracasado en la demostración de la configuración de las causales ${ }^{53}$.

\section{Armonización internacional y perspectiva proarbitraje}

Para la CSJ, en virtud de esta regla, el estudio de reconocimiento y anulación debe realizarse bajo los lineamientos del sistema jurídico internacional, con el fin de tener una interpretación armoniosa con la hermenéutica de las normas que regulan estos procedimientos en otros países, coincidente con el propósito de la CNY y pro-reconocimiento ${ }^{54}$.

Inicialmente, el desarrollo de esta regla puede observarse a través de algunas sentencias en que la CSJ resolvió solicitudes de exequátur y en las cuales definió y desarrolló el concepto de orden público empleando algunos lineamientos internacionales.

En efecto, desde la sentencia de fecha 5 de noviembre de $1996^{[55]}$, la CSJ empezó a adoptar esta perspectiva de armonización internacional, apartándose, en sus propias palabras, de una posición que solo se regía por criterios nacionales ${ }^{56}$. Al analizar el concepto de orden público, determinó que el análisis de su vulneración constituye "un problema de justicia que obliga a advertir la evolución de ese concepto en el espacio y en el tiempo, examen que por lo tanto ha de adecuarse siempre a criterios jurídicos actualmente en vigor [...] [al] 'orden público' dinámico, tolerante y constructivo que reclama la comunidad internacional en el mundo contemporáneo" 57 .

Posteriormente, en la sentencia de fecha 30 de enero de $2004^{[58]}$, la CSJ determinó que "el concepto de orden público tiene existencia propia y no comprende por regla general las denominadas normas imperativas internas, porque si lo fueran harían imposible la aplicación del derecho internacional privado".

53 Ídem.

54 CSJ, Cas. Civil. Sent. SC 9909-2017, jul. 12/2017, 21: “(1) interpretación pro-internacional; (2) principio pro-ejecución o pro-reconocimiento".

55 CSJ, Cas. Civil. Sent. nov. 5/1996, exp. 6130. MP: Carlos Esteban Jaramillo Schloss. Asunto: Solicitud de exequátur.

56 Así lo indicó la propia sentencia al señalar que "la Corte se ve en la necesidad de apartarse de los criterios por ella seguidos en algunas decisiones anteriores como la contenida en la sentencia de fecha diecisiete (17) de mayo de 1978 (G. J., tomo CLVIII, págs. 76 a 80), el juez local no puede evaluar una sentencia extranjera teniendo en cuenta tan sólo disposiciones generales de la estirpe de las consagradas por los arts. 19 y 20 del C. Civil, como si ellas constituyeran una pauta dogmática". Ídem.

57 Ídem.

58 CSJ, Cas. Civil. Sent. ene. 30/2004, rad. 100102030002002-0008-01. MP: José Fernando Ramírez. Asunto: exequátur, 10. 
Más adelante, en la sentencia de fecha 27 de julio de $2011^{[59]}$, arribó a una definición de orden público con base en la perspectiva del derecho internacional privado y a través de un análisis de derecho comparado, donde se refirió al derecho alemán y a la jurisprudencia del Tribunal Supremo español, de la Corte Suprema suiza y de la Corte de Apelaciones de Estados Unidos ${ }^{60}$. Con fundamento en lo anterior, la CSJ estableció que "en principio, el desconocimiento de una norma imperativa propia del 'foro' del juez del exequátur, per se, no conlleva un ataque al mencionado instituto"61.

Con posterioridad a la entrada en vigor de la Ley 1563, en las sentencias SC $8453-2016^{[62]}$, SC $12467-2016^{[63]}$, SC 9909-2017 ${ }^{[64]}$ y SC 877-2018 ${ }^{[65]}$, la CSJ determinó que las normas procesales aplicables a la anulación y el reconocimiento de laudos arbitrales son exclusivamente la Sección Tercera de la Ley 1563 y las normas internacionales incorporadas al sistema jurídico colombiano sobre arbitraje internacional. Este razonamiento fue soportado en su interpretación de los artículos 64 de la Ley $1563^{[66-67]}$ y 605 del Código General del Proceso (CGP) ${ }^{68}$, ya que para la CSJ el CGP "no resulta aplicable a la materia, pues sólo podrán considerarse las reglas especialmente diseñadas para el reconocimiento de laudos arbitrales proferidos en el extranjero" y los tratados internacionales ratificados por el país ${ }^{69}$.

De forma más reciente, en la sentencia SC 001-2019, la CSJ reconoció que si bien estos procedimientos están regulados por la legislación de cada país, internacionalmente se ha buscado su estandarización, lo cual se ha expresado en la

CSJ, Cas. Civil. Sent. jul. 27/2011, rad. 11001-0203-000-2007-01956-00. MP: Ruth Marina Díaz Rueda. Asunto: exequátur.

lbíd., 38-42.

Ibíd., 47.

CSJ, Cas. Civil. Sent. jun. 24/2016, SC 8453-2016, rad. 11001-02-03-000-2014-02243-00. MP: Ariel Salazar Ramírez. Asunto: Reconocimiento de laudo arbitral, 8.

CSJ, Cas. Civil. Sent. sept. 7/2016, SC 12467-2016, rad. 11001-02-03-000-2014-02737-00. MP: Luis Armando Tolosa Villabona. Asunto: Reconocimiento de laudo arbitral, 20.

CSJ, Cas. Civil. Sent. SC 9909-2017, jul. 12/2017, 21.

CSJ, Cas. Civil. Sent. mar. 23/2018, SC 877-2018, rad. 11001-02-03-000-2017-00080-00. MP: Ariel Salazar Ramírez. Asunto: Reconocimiento de laudo arbitral, 9.

El artículo 64 de la Ley 1563 establece: “En la interpretación del arbitraje internacional habrán de tenerse en cuenta su carácter internacional y la necesidad de promover la uniformidad de su aplicación y la observancia de la buena fe".

CSJ, Cas. Civil. Sent. SC 9909-2017, jul. 12/2017, 22.

“Artículo 605. Efectos de las sentencias extranjeras. [...] El exequátur de laudos arbitrales proferidos en el extranjero se someterá a las normas que regulan la materia." Ley 1564 de 2012, 12 de julio. Diario Oficial 48.489.

Ibíd., 16. 
Ley Modelo y en la CNY70-71. De acuerdo con la CSJ, el proceso de reconocimiento es un fenómeno internacional, "pues ni el laudo ni sus efectos pierden su condición de extranjeros por el hecho de que aquel sea reconocido y ejecutado por una corte colombiana"72. Igualmente, para la CSJ el objetivo de la Ley 1563 fue insertar las normas colombianas en el marco de los estándares previstos en el sistema jurídico internacional ${ }^{73}$, por lo cual la hermenéutica de las causales de anulación que la ley contiene debe tener en cuenta los criterios aceptados internacionalmente para la $\mathrm{CNY}^{74}$.

Para la CSJ, estos criterios internacionales han sido identificados por Gary Born, a quien citó de forma expresa con el fin de señalar que si bien la CNY no limita el alcance de la revisión de los tribunales nacionales en sede de anulación, la interpretación más adecuada es que "lo hace indirectamente al exigir que los estados contratantes [...] reconozcan los acuerdos para arbitrar [...] De acuerdo con esto, algunos tribunales han llegado a la conclusión [...] de que las acciones para anular los laudos [... ] deben limitarse a los motivos especificados en el artículo V"75.

Esta posición sostenida por la CSJ en las anteriores sentencias contiene elementos de análisis que la doctrina ha identificado que son el propósito de la CNY, a saber, unificar la práctica del reconocimiento y ejecución para remover los obstáculos nacionales y judiciales del arbitraje ${ }^{76}$.

Igualmente, una posición similar se ha acogido en el campo internacional por diferentes cortes nacionales, que han buscado la armonización internacional al interpretar la causal de orden público. Al respecto, los profesores Julian Lew y Loukas Mistelis han sostenido que en la mayoría de decisiones del orden internacional se ha reconocido que un laudo arbitral solo podrá ser desconocido cuando vulnere una norma de orden público internacional77. 
Sobre este punto existe un caso hito de la Suprema Corte de Estados Uni$\operatorname{dos}^{78}$, donde se sostuvo que "[I]a anulación de tal acuerdo en el caso frente a nosotros reflejaría un concepto parroquial según el cual todas las disputas deban ser resueltas bajo nuestras leyes y en nuestras cortes. No podemos tener intercambio y comercio en mercados mundiales y en aguas internacionales exclusivamente en nuestros términos, gobernados por nuestras leyes, y resueltos por nuestras cortes". Por su parte, la Corte Europea de Justicia ha acogido una interpretación similar ${ }^{79}$.

\section{B) Hacia una visión internacional del arbitraje comercial internacional}

De acuerdo con la revisión jurisprudencial efectuada, la CSJ ha determinado que su competencia en el reconocimiento y la anulación debe guiarse y está limitada por el principio de mínima intervención judicial, según el cual el análisis debe excluir una revisión sustancial, ser taxativo y estar en armonía internacional. Como puede observarse en las decisiones citadas, la CSJ acogió en instrumentos internacionales de hard law y soft law la jurisprudencia y la doctrina internacionales.

En este punto es pertinente resaltar que las reglas que ha adoptado la CSJ para efectuar su análisis en los procedimientos de reconocimiento y anulación coinciden con los cánones de interpretación que la doctrina internacional ha identificado que se siguen en el campo internacional sobre la CNY. En efecto, el profesor Marike Paulsson realizó una lista de las reglas de interpretación relevantes del artículo $\mathrm{V}$ de la CNY que se han venido adoptando internacionalmente, con base en el texto de la convención, su contexto, su propósito y la aplicación judicial que se le ha dado ${ }^{80}$. Dentro de estas reglas se encuentran las siguientes ${ }^{81}$ :

1. Las cortes no pueden revisar los méritos del laudo;

2. Las causales son exhaustivas y su interpretación debe ser restrictiva; y

3. Debe haber una actitud pro-enforcement, es decir, que contribuya al propósito de la convención: la efectividad del arbitraje internacional.

Corte Suprema de Estados Unidos. Caso de Scherk v Alberto-Culver Co. 17 de junio de 1974. Citación oficial: 417 U.S. 506.

Corte Europea de Justicia. Caso de Eco Swiss China Time Ltd. v Benetton International N.V. $1 .^{\circ}$ de junio de 1999. Número de caso: C-126-97.

80 Marike Paulsson, The 1958 New York Convention in Action (Kluwer Law International, 2016), 165.

81 Ibíd., 166. 
De esta manera, las reglas derivadas del principio de mínima intervención y establecidas por la CSJ corresponderían con los cánones de interpretación listados y que la doctrina ha identificado que imperan en el espacio internacional en diferentes cortes nacionales y en la doctrina extranjera.

\section{La interpretación de algunas causales de denegación de reconocimiento y anulación}

Con fundamento en el principio de mínima intervención y sus reglas derivadas, la CSJ ha interpretado algunas causales contenidas en los artículos 108 y 112 de la Ley 1563, en especial (1) la invalidez del pacto arbitral, (2) la incongruencia, (3) la separación del procedimiento acordado y (4) el orden público internacional. En esta sección se hará una revisión enunciativa del entendimiento que la CSJ le ha dado a cada una de estas causales y se expondrá cómo para su interpretación se ha basado en los criterios internacionales existentes y ha coincidido con ellos.

\section{A) Invalidez del pacto arbitral ${ }^{82}$}

En la sentencia SC 001-2019 ${ }^{[83]}$ la CSJ señaló que para estudiar la eficacia de un pacto debe determinarse cuál es el derecho aplicable a él; para tal fin deberá estarse a lo acordado por las partes y, en caso de ausencia de acuerdo, la determinación de los requisitos se regulará por las normas internacionales.

En efecto, para la CSJ la norma aplicable es, en primer lugar, el artículo segundo de la CNY, el cual establece que un pacto arbitral debe ser reconocido cuando conste por escrito, recaiga sobre materias arbitrables, exista capacidad, consentimiento libre de vicios y el cumplimiento de otros requisitos formales ${ }^{84-85}$. En segundo lugar, se debe tener en cuenta la doctrina internacional, en cuanto señala que en el análisis de eficacia del pacto arbitral debe adoptarse el enfoque

\footnotetext{
82 Literal a del numeral 1 del artículo 108 y numeral i del literal a del artículo 112 de la Ley 1563.

83 CSJ, Cas. Civil. Sent. SC 001-2019, ene. 15/2019, 27.

84 lbíd., 28-29.

85 Franco Ferrari y Friedrich Rosenfeld, "Límites a la autonomía de las partes en arbitraje internacional”. Arbitraje: Revista de Arbitraje Comercial y de Inversiones n. ${ }^{\circ} 10$ (2017): 339. Citado por CSJ, Cas. Civil. Sent. SC 001-2019, ene. 15/2019, 29.
} 
proarbitraje ${ }^{86}$. Posteriormente, debe acudirse al artículo 69 de la Ley 1563, en la medida en que otorga efectos jurídicos a cualquier pacto arbitral, al margen de su forma de expresión ${ }^{87}$.

Así, siguiendo su regla de armonización internacional y proarbitraje, para la interpretación de esta causal la CSJ ha recurrido a las fuentes normativas internacionales y solo después a las normas nacionales contenidas en la Ley 1563.

\section{B) Incongruencia ${ }^{88}$}

En palabras de la CSJ, la interpretación de esta causal se ha apartado de la visión tradicional que "clama porque la causal se aplique tanto al desconocimiento de los límites del pacto arbitral, como a la resolución de asuntos que no fueron planteados por las partes en sus intervenciones principales" ${ }^{19-90}$. Siguiendo esta senda, en la sentencia SC 5207-2017 ${ }^{[91]}$ se sostuvo que la causal de incongruencia implica acreditar que la decisión arbitral se refirió a un litigio ajeno a la cláusula compromisoria, no a una falta de congruencia entre el laudo y la demanda.

Según la sentencia SC 001-2019, "la incongruencia que puede dar lugar a la anulación de un laudo está referida al alcance del pacto arbitral, no así frente a la demanda o su contestación"92. Para la CSJ esta interpretación busca "resguardar el carácter excepcional de las causales de anulación y de dar prevalencia al principio pro-arbitraje" 93 , y obedece a que la Ley 1563 no hace referencia alguna a los escritos de demanda o contestación, "por lo que una interpretación restrictiva impide ampliar su contenido para cobijar estos últimos"94. International Commercial Arbitration (Nueva York: United Nations, 2012), 142. Citado por CSJ, Cas. Civil. Sent. SC 001-2019, ene. 15/2019, 29-30.

CSJ, Cas. Civil. Sent. SC 001-2019, ene. 15/2019, 30.

Literal c del numeral 1 del artículo 108 y numeral iii del literal a del artículo 112 de la Ley 1563.

CSJ, Cas. Civil. Sent. SC 001-2019, ene. 15/2019, p. 32.

90 En el ámbito nacional, la CSJ ha sostenido que la incongruencia "se presenta, entonces, cuando el juez decide el caso por fuera de las pretensiones o excepciones probadas (extra petita), o más allá de lo pedido (ultra petita), o cercenando lo que fue objeto de alegación y demostración (citra petita)". Al respecto, véase CSJ. Sent. Cas. Civil. Sent. sept. 26/2017, SC 15211-2017, rad. 11001-31-03-0192011-00224-01. MP: Aroldo Wilson Quiroz. Asunto: Recurso extraordinario de casación, 9-10. 
Conforme a lo anterior, la CSJ expresamente ha acogido las reglas de taxatividad y armonización internacional, al adoptar una interpretación restrictiva y proarbitraje de la causal de incongruencia.

\section{C) El procedimiento arbitral no se ajusta al acordado entre las partes 95}

Respecto de esta causal, en la sentencia SC 17655-2017 la CSJ señaló que el legislador "ha otorgado supremacía a la voluntad de las partes en la materia en cuestión, procurando con ello limitar las posibilidades para denegar el reconocimiento y ejecución de los laudos extranjeros por irregularidades procesales determinadas en las leyes nacionales"96.

Igualmente, la CSJ ha señalado expresamente que solo admite errores procesales graves, de manera que su prosperidad es excepcional, pues el proceso arbitral se caracteriza por ser flexible y, en consecuencia, solo una vulneración grave a este puede generar la anulación del laudo97.

En la interpretación de esta causal la CSJ citó la jurisprudencia internacional recogida por la CNUDMI, según la cual su prosperidad requiere errores de procedimiento de un alto grado de gravedad, por ejemplo, violaciones importantes al debido proceso ${ }^{98}$.

En el ámbito internacional, la visión prevalente coincide con esta perspectiva de la CSJ. En efecto, sobre esta causal los profesores Lew y Mistelis han sostenido que, por regla general, en diferentes cortes extranjeras prevalece la visión según la cual una irregularidad procesal por sí misma no invalidaría el laudo pues sería necesaria la existencia de una injusticia significativa ${ }^{99}$.

\section{D) Orden público internacional ${ }^{100}$}

En la sentencia SC $8453-2016^{[101]}$, la parte convocada solicitó que se negara el reconocimiento del laudo arbitral toda vez que la cláusula compromisoria era ineficaz

Literal $d$ del numeral 1 del artículo 108 y numeral iv del literal a del artículo 112 de la Ley 1563.

CSJ, Cas. Civil. Sent. SC 17655-2017, oct. 30/2017, 31

CSJ, Cas. Civil. Sent. SC 001-2019, ene. 15/2019, 33.

United Nations Commission on International Trade Law, Digest of Case Law, 142.

Lew y Mistelis, Comparative International Commercial Arbitration, 675

Literal $b$ del numeral 2 del artículo 108 y numeral i del literal $b$ del artículo 112 de la Ley 1563.

CSJ, Cas. Civil. Sent. jun. 24/2016, SC 8453-2016. 
de acuerdo, entre otras normas, con el artículo 1328 del Código de Comercio ${ }^{102}$, pues en el contrato se estipuló que "la ley aplicable a éste sería la del Estado de Texas, Estados Unidos de América, lo que contrariaba lo previsto en la última de esas normas, que es de orden público y conforme a la cual '[...] los contratos de agencia comercial que se ejecuten en el territorio nacional quedan sujetos a las leyes colombianas'"'103.

En lo que respecta a la causal de denegación de orden público, para resolver la CSJ determinó que esta causal se encuentra prevista dentro de "las causales que la autoridad competente para otorgar el reconocimiento podrá declarar de manera oficiosa fundándose en normas de derecho interno, siempre que las encuentre comprobadas" y que también está en la Ley 1563, con base en una reproducción de la CNY, de la misma forma que la Convención Interamericana sobre Arbitraje Comercial Internacional104.

Sentado lo anterior, la CSJ se basó en la doctrina internacional y citó la Resolución 2 de 2002 de la Asociación de Derecho Internacional ${ }^{105}$ para llegar a la conclusión de que "únicamente si el laudo arbitral para el que se pide el reconocimiento lesiona los valores y principios básicos o fundamentales en que se inspiran las instituciones jurídicas del ordenamiento patrio, podría denegarse su reconocimiento" 106 .

Además, aplicó la clasificación internacional de orden público internacional sustancial y procesal para analizar el caso concreto, con base en la clasificación de la Asociación de Derecho Internacional ${ }^{107}$, y diferenció el orden público internacional del interno de cada Estado ${ }^{108}$.

Con fundamento en lo expuesto, la CSJ sostuvo que el laudo arbitral estudiado no transgredía el orden público internacional, pues si bien el artículo 1328 del Código de Comercio "restringe la aplicación de normas foráneas a los contratos de agencia ejecutados en territorio nacional, en tanto no corresponde a una disposición que involucre los intereses, principios y valores fundamentales del Estado

102 "Artículo 1328. Sujeción a las leyes colombianas. Para todos los efectos, los contratos de agencia comercial que se ejecuten en el territorio nacional quedan sujetos a las leyes colombianas. Toda estipulación en contrario se tendrá por no escrita". Decreto 410 de 1971, 16 de junio. Diario Oficial 33.339.

103 lbíd., 5.

104 Ibíd., 22. Convención Interamericana sobre Arbitraje Comercial Internacional, 30 de enero de 1965.

105 ILA, Resolución 2/2002 Arbitraje Internacional Comercial.

106 Ibíd., 35.

107 Ibíd., 34-35.

108 Ibíd., 39. 
colombiano no puede considerársele como parte del «orden público internacional» que puede aducirse como causal para denegar el reconocimiento del laudo"109.

Además, la CSJ estableció que en el caso del orden público internacional "prevalece el cumplimiento de los compromisos adquiridos por el Estado al hacerse parte de las Convenciones de New York y de Panamá sobre «el Reconocimiento y la Ejecución de las Sentencias Arbitrales Extrajeras» y «Arbitraje Comercial Internacional»"110.

Más adelante, en la sentencia SC 9909-2017, la CSJ conoció de un trámite de solicitud reconocimiento donde se alegaba la vulneración del orden público internacional sobre la base de que un árbitro había infringido las normas del deber de información contenidas en la sección de arbitraje nacional de la Ley 1563. Para resolver el caso, la CSJ realizó un análisis pormenorizado del orden público ${ }^{111}$, donde distinguió sus diferentes acepciones, a saber, de dirección, de protección, nacional, trasnacional e internacional ${ }^{112}$; a partir de esto, señaló que los elementos que integran el orden público internacional son los principios fundamentales de las instituciones como el abuso del derecho, la buena fe y el debido proceso ${ }^{113}$.

Posteriormente, la CSJ encontró necesario acudir a la regla de armonización internacional y, citando una sentencia de la Corte de Apelaciones del Segundo Circuito de Estados Unidos ${ }^{114}$, sostuvo que se requería una interpretación restrictiva del concepto pues de lo contrario se desconocería el fin de la CNY115. En este contexto, se detuvo a analizar el orden público de naturaleza procesal, en específico el debido proceso expresado en la imparcialidad del juzgador, y señaló que su vulneración no puede determinarse con base en los criterios nacionales de la Ley 1563 sobre deber de información, sino a partir de estándares internacionales que sean razonables.

109 Ibíd., 41.

110 Ídem.

111 Este análisis fue reiterado en su totalidad en CSJ, Cas. Civil. Sent. SC 001-2019, ene. 15/2019, 33.

112 “[... ] se habla de orden público (1) de dirección, para denotar las normas que regulan el logro de los objetivos del Estado; (2) de protección, relativo a los instrumentos de promoción de actividades o personas; (3) nacional, que incluye todos los principios y cánones que establecen las reglas mínimas de funcionamiento de la sociedad; (4) internacional, que denota los valores esenciales de un Estado, que no son susceptibles de negociación en el concierto internacional; (5) trasnacional, representado en los principios compartidos por todas las naciones civilizadas; (6) verdaderamente internacional, vinculado a las nociones mínimas de justicia y moralidad que son aceptadas por diferentes sociedades alrededor del mundo." CSJ, Cas. Civil. Sent. SC 9909-2017, jul. 12/2017, 42.

113 CSJ, Cas. Civil. Sent. SC 12467-2016, sept. 7/2016, 13.

114 Corte de Apelaciones del Segundo Circuito de Estados Unidos. Caso Parsons Whittemore Overseas Co Inc. v Société Générale de L'Industrie du Papier (RAKTA). 23 de diciembre de 1974. Número oficial: 508 F.2d 969.

115 CSJ, Cas. Civil. Sent. SC 9909-2017, jul. 12/2017, 44. 
Así, aplicó las Directrices sobre Conflictos de Interés en Arbitraje Internacional de la International Bar Association ${ }^{116}$, para determinar las situaciones que afectan la objetividad de los árbitros, bajo el entendido de que son una compilación realizada por expertos que refleja la práctica de la comunidad arbitral global|117. Con fundamento en estas directrices determinó que no había existido una vulneración del orden público internacional pues no consagraban como motivo vulnerador de la imparcialidad del árbitro la situación en cuestión.

Sobre esta última sentencia, la profesora Margaret Moses ha sostenido que es un ejemplo de cómo una corte ha tomado en cuenta el contexto transnacional para determinar una debida aplicación del orden público ${ }^{118}$. Según Moses, a pesar de que la CSJ concedió que el reconocimiento bajo las circunstancias analizadas podría vulnerar el orden público doméstico de Colombia, "concluyó que el orden público internacional del país era diferente y que la corte debía tomar en cuenta a las autoridades internacionales para determinar si existía una violación"119. De esta forma, para Moses la CSJ "miró hacia afuera, hacia las prácticas internacionales, basándose en un instrumento internacional de soft law para determinar la política pública internacional de su país"120.

Conforme a la doctrina internacional, la anterior perspectiva de la CSJ sería la regla general en el ámbito internacional. Sobre este punto, Gary Born ${ }^{121}$ ha indicado que a pesar del carácter potencialmente amplio del concepto, las cortes en la mayoría de las jurisdicciones se han rehusado a decretar esta excepción; por el contrario, han partido de reconocerle un carácter restringido. Así mismo, el profesor Albert Jan van den Berg ${ }^{122}$ ha señalado que la regla general de interpretación que se aplica a las causales, incluyendo la de orden público, es la de una interpretación estrecha.

De la misma forma, diversas cortes extranjeras han reconocido que debe darse una dimensión deslocalizada y restrictiva al orden público ${ }^{123}$. Por ejemplo,

1162014 IBA, Directrices sobre Conflictos de Interés en Arbitraje Internacional.

117 Ibíd., 50-51.

118 Margaret Moses, "Public Policy under the New York Convention: National, International, and Transnational" en 60 Years of the New York Convention: Key Issues and Future Challenges, editado por Katia Fach y Ana López (Kluwer Law International, 2019), 175.

119 Ídem.

120 Ídem.

121 Born, International Arbitration, 479.

122 Albert Jan van den Berg, "The New York Convention of 1958: An Overview" en Enforcement of Arbitration Agreements and International Arbitral Awards - The New York Convention Practice, editado por Emanuel Gaillard and Domenico Di Pietro (United Kingdom: Cameron May, 2008), 18.

123 Born, International Arbitration, 710. 
en Estados Unidos la Corte del Distrito de Nueva York en el caso de Parsons Whittemore Overseas Co Inc. v Société Générale del'Industrie du Papier sostuvo que la excepción de orden público debe ser interpretada de forma restringida y que el reconocimiento solo debe negarse sobre la base de que este viole las nociones más básicas de moralidad y justicia ${ }^{124}$. Igualmente, otras cortes de este país han señalado que solo podrían negar el reconocimiento de un laudo extranjero cuando vulnere las nociones fundamentales de lo decente y lo justo en Estados Unidos o en aquellos casos en que el contrato, como fue interpretado por los árbitros, viole una norma de orden público que esté definida y establecida con base en la ley o el precedente, no con fundamento en meras consideraciones generales de interés público ${ }^{125}$.

\section{E) Una hermenéutica consecuente con el principio de mínima intervención}

Vista la anterior exposición descriptiva de la jurisprudencia de la CSJ, es posible observar que al interpretar las causales la CSJ se ha basado en el principio de mínima intervención judicial y sus reglas. Igualmente, al abordar las causales, la CSJ se ha basado y ha coincidido con los criterios internacionales más empleados para su interpretación.

A título de mero resumen de lo sostenido por la CSJ, se tiene lo siguiente:

1. Frente a la causal de invalidez del pacto arbitral la CSJ ha determinado, en desarrollo de la armonización internacional y una visión proarbitraje, que debe darse aplicación prioritaria a las fuentes internacionales y posteriormente a las nacionales;

2. Respecto de la causal de incongruencia, la CSJ ha adoptado una interpretación taxativa, restrictiva y proarbitraje que se diferencia del entendimiento de la congruencia en el derecho nacional, pues se somete al alcance del pacto arbitral y no a los límites que imponen la demanda y la contestación;

3. Frente a la casual de no ajustarse al procedimiento acordado por las partes, la CSJ ha condicionado su prosperidad a casos graves y excepcionales de injusticia, de acuerdo con una visión proarbitraje; y

124 Citado por Born, International Arbitration, 710.

125 Louis del Duca y Nancy Welsh, "Enforcement of Foreign Arbitration Agreements and Awards: Application of the New York Convention in the United States". The American Journal of Comparative Law, n. ${ }^{\circ} 62$ (2014): 88, https://scholarship.law.tamu.edu/facscholar/943. 
4. Al interpretar la causal de orden público se ha apartado de nociones eminentemente locales, y ha recurrido a fuentes y criterios de interpretación internacionales que optan por un entendimiento más restrictivo del concepto.

\section{Algunas conclusiones relevantes}

La CSJ ha establecido a través de su jurisprudencia que su competencia en el reconocimiento y la anulación de laudos extranjeros debe guiarse y está limitada por el principio de mínima intervención judicial. Con fundamento en este principio, la CSJ ha establecido que su análisis debe seguir las siguientes reglas:

1. Debe excluir una revisión sustancial y de los méritos del laudo arbitral;

2. Limitarse taxativamente a las causales establecidas en la ley, así como interpretarlas de forma restrictiva; $y$

3. Estar en armonía con el derecho internacional, acogiendo una postura proarbitraje.

En su jurisprudencia, la CSJ ha recurrido a instrumentos internacionales de hard law y soft law, así como también a la jurisprudencia y la doctrina internacionales. Además, las reglas que ha adoptado se basan en los cánones de interpretación existentes en el espacio internacional frente a la denegación de reconocimiento y anulación de laudos arbitrales extranjeros, y coinciden con ellos.

Con fundamento en el principio de mínima intervención y en aplicación de las reglas derivadas de él, la CSJ ha interpretado las causales específicas de denegación de reconocimiento y anulación.

En este sentido, frente a la causal de invalidez del pacto arbitral ha determinado que debe darse aplicación prioritaria a las fuentes internacionales y posteriormente a las nacionales; respecto de la incongruencia, le ha dado una interpretación taxativa, restrictiva y proarbitraje que se diferencia de la visión de la congruencia en el derecho nacional; en cuanto a la causal de no ajustarse el procedimiento al pactado por las partes, ha condicionado su prosperidad a casos graves y excepcionales de injusticia; $y$, por último, al entender el orden público internacional ha recurrido a criterios internacionales que optan por un entendimiento restrictivo del concepto. 


\section{Referencias}

Asociación de Derecho Internacional. "Resolución 2/2002, Arbitraje Internacional Comercial".

Barragán, Luis Alfredo. "El recurso extraordinario de anulación". En Arbitraje $360^{\circ}$ La práctica del litigio arbitral. Aspectos contractuales y procesales. Editado por Hernando Herrera y Fabricio Mantilla. Bogotá: Editorial Ibáñez, 2017.

Blackaby, Nigel, Hunter, Martin, Partasides, Constantine, Redfern, Alan. Redfern and Hunter on International Arbitration. Oxford: Oxford, 2009.

Born, Gary. International Arbitration: Law and practice. Alphen aan den Rijn: Kluwer Law International, 2012.

Comisión de Naciones Unidas para el Derecho Mercantil Internacional. Ley Modelo sobre Arbitraje Comercial Internacional. 1985.

Convención Interamericana sobre Arbitraje Comercial Internacional, 30 de enero de 1965.

Convención sobre el Reconocimiento y Ejecución de las Sentencias Arbitrales Extranjeras, 10 de junio de 1958.

Corte de Apelaciones del Segundo Circuito de Estados Unidos. Caso Parsons Whittemore Overseas Co Inc v Société Générale de L'Industrie du Papier (RAKTA). 23 de diciembre de 1974. Número oficial: 508 F.2d 969.

Corte Europea de Justicia. Caso de Eco Swiss China Time Ltd. v Benetton International N.V. $1 .^{\circ}$ de junio de 1999. Número de caso: C-126-97.

Corte Suprema de Estados Unidos. Caso de Scherk v Alberto-Culver Co. 17 de junio de 1974. Citación oficial: 417 U.S. 506.

CSJ, Cas. Civil. Sent. nov. 5/1996, exp. 6130. MP: Carlos Esteban Jaramillo Schloss. Asunto: Exequátur.

CSJ, Cas. Civil. Sent. ene. 30/2004, rad. 1100102030002002-0008-01. MP: José Fernando Ramírez. Asunto: Exequátur.

CSJ, Cas. Civil. Sent. jul 21/2005, rad. 1101-02-03-000-2004-00034-01. MP: Edgardo Villamil Portilla. Asunto: Recurso extraordinario de revisión.

CSJ, Cas. Civil. Sent. jul. 27/2011, rad. 11001-0203-000-2007-01956-00. MP: Ruth Marina Díaz Rueda. Asunto: Exequátur. 
CSJ, Cas. Civil. Sent. abr. 21/2014, SC 4766-2014, rad. 11001-0203-0002012-01428-00. MP: Ruth Marina Díaz Rueda. Asunto: Recuso extraordinario de revisión.

CSJ, Cas. Civil. Sent. jun. 24/2016, SC 8453-2016, rad. 11001-02-03-0002014-02243-00. MP: Ariel Salazar Ramírez. Asunto: Reconocimiento de laudo arbitral.

CSJ, Cas. Civil. Sent. sept. 7/2016, SC 12467-2016, rad. 11001-02-03000-2014-02737-00. MP: Luis Armando Tolosa Villabona. Asunto: Reconocimiento de laudo arbitral.

CSJ, Cas. Civil. Sent. abr. 18/2017, SC 5207-2017, rad. 11001-0203-0002016-01312-00. MP: Luis Alonso Rico Puerta. Asunto: Recurso extraordinario de anulación de laudo arbitral.

CSJ, Cas. Civil. Sent. jul. 12/2017, SC 9909-2017, rad. 11001-02-03-0002014-01927-00. MP: Aroldo Wilson Quiroz. Asunto: Reconocimiento de laudo arbitral.

CSJ. Sent. Cas. Civil. Sent. sept. 26/2017, SC 15211-2017, rad. 1100131-03-019-2011-00224-01. MP: Aroldo Wilson Quiroz. Asunto: Recurso extraordinario de casación.

CSJ, Cas. Civil. Sent. oct. 30/2017, SC 17655-2017, rad. 11001-0203-000-2016-00479-00. MP: Ariel Salazar Ramírez. Asunto: Reconocimiento de laudo arbitral.

CSJ, Cas. Civil. Sent. mar. 23/2018, SC 877-2018, rad. 11001-02-03-0002017-00080-00. MP: Ariel Salazar Ramírez. Asunto: Reconocimiento de laudo arbitral.

CSJ, Cas. Civil. Sent. dic. 19/2018, SC 5677-2018, rad. 11001-02-03000-2017-03480-00. MP: Margarita Cabello Blanco. Asunto: Recurso extraordinario de anulación de laudo arbitral.

CSJ, Cas. Civil. Sent. ene. 15/2019, SC 001-2019, rad. 11001-02-03-0002016-03020-00. MP: Aroldo Wilson Quiroz. Asunto: Recurso extraordinario de anulación de laudo arbitral.

CSJ, Cas. Civil. Auto ago. 1/2019, AC 3076-2019, rad. 11001-02-03-0002019-02452-00. MP: Aroldo Wilson Quiroz. Asunto: Recurso extraordinario de anulación de laudo arbitral.

Decreto 410 de 1971, 16 de junio. Diario Oficial 33.339.

Del Duca, Louis y Welsh, Nancy. "Enforcement of Foreign Arbitration Agreements and Awards: Application of the New York Convention in the United States". The American Journal of Comparative Law, n. 62 (2014): 69-95. https://scholarship.law.tamu.edu/facscholar/943. 
Ferrari, Franco, y Rosenfeld, Friedrich. "Límites a la autonomía de las partes en arbitraje internacional". Arbitraje: Revista de Arbitraje Comercial y de Inversiones 10, n. 2 (2017): 335 386. DOI 10.19194/arbitraje raci.10.2.01.

Gaillard, Emmanuel y Siino, Benjamin. "Enforcement under the New York Convention". En The Guide to Challenging and Enforcing Arbitration Awards. Editado por William Rowley. 86-99. London: Law Business Research, 2019.

Herrera, Fredy y Felipe González. "Evolución de la jurisprudencia de la Corte Suprema de Justicia en materia arbitral". YouTube. 13 de febrero de 2019. https://www.youtube.com/watch?v=9rn9ArsRCmA\&t=1263s.

International Bar Association. "Directrices sobre Conflictos de Interés en Arbitraje Internacional”. 2014.

International Chamber of Commerce. "ICC Dispute Resolution Bulletin 2018 Issue 2. Extract”. Julio de 2018. https://cdn.iccwbo.org/content/ uploads/sites/3/2018/07/2017-icc-dispute-resolution-statistics.pdf.

International Chamber of Commerce. "ICC celebrates case milestone, announces record figures for 2019". 9 de enero de 2020. https://iccwbo. org/media-wall/news-speeches/icc-celebrates-25000th-case-milesto ne-and-announces-record-figures-for-2019/.

Lew, Julian y Mistelis Loukas. Comparative International Commercial Arbitration. Kluwer Law International, 2003.

Ley 39 de 1990, 20 de noviembre. Diario Oficial 39.587.

Ley 1563 de 2012, 12 de julio. Diario Oficial 48.489.

Ley 1564 de 2012, 12 de julio. Diario Oficial 48.489.

Lozada, Nicolás y Otero, Hernando. "Reconocimiento y ejecución de laudos arbitrales internacionales en Colombia ¡Adiós exequátur!”, en Arbitraje $360^{\circ}$ La práctica del litigio arbitral. Aspectos contractuales y procesales. Editado por Hernando Herrera y Fabricio Mantilla. Bogotá: Editorial Ibáñez, 2017.

Monroy, Marco. Arbitraje Comercial Nacional e Internacional. Bogotá: Librería Ediciones El Profesional, 2017.

Moses, Margaret. "Public Policy under the New York Convention: National, International, and Transnational". En 60 Years of the New York Convention: Key Issues and Future Challenges. Editado por Katia Fach y Ana López. 169-184. Kluwer Law International, 2019. 
Moses, Margaret. The principles and practices of international commercial arbitration. New York: Cambridge University Press, 2008.

Paulsson, Marike. The 1958 New York Convention in Action. Kluwer Law International, 2016.

Pavic, Vladimir. "Annulment of arbitral awards in international commercial arbitration". En Investment and Commercial Arbitration - Similarities and Divergences. Editado por Christina Knahr, Christian Koller, Walter Rechberger y August Reinisch. 131-152. The Netherlands: Eleven International Publishing, 2010.

United Nations Commission on International Trade Law. Digest of Case Law on the Model Law on International Commercial Arbitration. Nueva York: United Nations, 2012.

United Nations Comission on International Trade Law. "Status: Convention on the Recognition and Enforcement of Foreign Arbitral Awards". https://uncitral.un.org/en/texts/arbitration/conventions/foreign_ar bitral_awards/status2.

United Nations Commission on International Trade Law. "Status: UNClTRAL Model Law on International Commercial Arbitration (1985), with amendments as adopted in 2006". https://uncitral.un.org/en/texts/ar bitration/modellaw/commercial_arbitration/status.

Van den Berg, Albert. "The New York Convention of 1958: An Overview". En Enforcement of Arbitration Agreements and International Arbitral Awards - The New York Convention Practice. Editado por Emanuel Gaillard and Domenico Di Pietro. United Kingdom: Cameron May, 2008. 